\title{
Using Videos and 3D Animations for Conceptual Learning in Basic Computer Units
}

\author{
Unal Cakiroglu \\ Karadeniz Technical University, Turkey \\ Huseyin Yilmaz \\ Ministry of National Education, Turkey
}

\begin{abstract}
This article draws on a one-semester study to investigate the effect of videos and 3D animations on students' conceptual understandings about basic computer units. A quasiexperimental design was carried out in two classrooms; videos and 3D animations were used in classroom activities in one group and those were used for homework in the other group. A three-phase concept test was used to determine the misconceptions, and clinical interviews were conducted to explain the improvements in conceptual understandings. The results indicated that using videos and 3D animations positively affected to remedy misconceptions and no significant difference was found among two groups in terms of conceptual change. Students' perspectives reflected that the videos and 3D animations facilitated the conceptual understanding via concretization, pausing, slowing down, replaying, and enlarging features. Along with the study findings, some implications were included for the use of videos and 3D animations in conceptual learning studies.
\end{abstract}

Keywords: Videos; 3D animations; Conceptual change; Basic computer units

\section{Introduction}

In the context of computer science education, computer departments of the vocational high schools play a crucial role in Turkey. In order to develop these students' IT skills and expertise, the knowledge and understanding of the nature and scope of the concepts about hardware and software units of computers come to the front. Since the change in IT and the ways of interacting with computers are rapidly changing, students' understandings and conceptions about computers become challenging task to investigate (Rucker \& Pinkwart, 2015). A common idea in conceptual understanding studies is that lack of conceptual understandings may shade and blur meaningful learning (Kuru \& Gunes, 2005). Therefore, conceptual understanding studies generally focus on determining and remedying misconceptions.

In this vein, especially from nineties in the computer science area, some efforts have been provided for examining students' conceptions about computers (Driver et al., 1994; Driver et al., 1996; Galloway, 1990; Oliver, 1994). With the advances of computer components, researchers tended to draw attention about the question: Do students really understand what a computer is? The samples of these studies were varied from 4-6 years to high school students. For instance, Crawford et al. (1999) used concept mapping as a means to define students' conceptions about the functions of the computers. Mumtaz (2002) interviewed a 
sample of primary school students and found that children who have experience of ICT at home as well as at the school have a better understanding of the computer system and its functions. Another study reported 7-8 years old students' conceptualization and perceptions about some applications of ICT (Read, MacFarlane, \& Casey, 2002). More specifically, Papastergiou (2005) examined the high school students' conceptual understandings about the Internet, and concluded that, students' experiences as users influence to their mental models. In another study emphasizing the experience of the use of computers; Hammond and Rogers (2006) presented some common misconceptions of students and addressed that all students had an awareness of basic input, output and storage devices. Focusing on remedying some misconceptions about computer units; Cakiroglu, Cebi, \& Bezir (2007) used animation-based means in order to enhance conceptual understandings of the students and reported some positive results. Recent research by Rucker \& Pinkwart (2015) highlighted five basic conceptions about computers: computers are intelligent, omniscient databases, wire networks, mechanical, and programmable. Within the studies about conceptual understandings, a wide variety of techniques are used in terms of determining and remedying the misconceptions. A brief explanation is provided in the following section.

\section{Determining and Remedying Misconceptions}

The studies focusing on the conceptualization generally begin with determining the lacks in conceptual understandings. To that end, conceptual understanding tests (Bernhard, 2000), achievement tests, open ended questions, interviews (Lanie, et al. 2004), observations, twophase scales, three-phase concept tests (Arslan, Cigdemoglu, \& Moseley, 2012; Kizlcik \& Gunes, 2011) are some common ways used to determine misconceptions. Some studies concluded that three-phase concept tests are more effective to determine misconceptions and it provides more valid measures (Chandrasegaran, Treagust, \& Mocerino, 2007; Caleon \& Subramaniam, 2010; Treagust, 1988).

In order to create appropriate learning environments for remedying misconceptions, it is necessary choosing a useful instructional approach and adapting instructional technologies in to the instructional process. In this regard, some useful ways were implemented to remedy misconceptions. Concept maps (Roussou, 2004), worksheets (Hay, 2007), conceptual changing texts, cooperative learning environments (Sanger \& Greenbowe, 2000; Van Boxtel, Van der Linden, \& Kanselaar, 2000), animations, simulations, analogies, courseware (Dalton, 2003, Rittle-Johnson, Siegler, \& Alibali, 2001) and web based instruction (Choi \& Johnson, 2005) were used in this context.

On the other hand; computer based materials were also suggested positive results for determining and remedying misconceptions (Baki, Kosa, \& Guven, 2011; Gal-Ezer \& Zur, 2004; Gurbuz \& Birgin, 2012; Huang, Liu, \& Shiu, 2008). In this vein, using videos (Feiereisen, Wong, \& Broderick, 2008; Vural \& Zelher, 2010) and 3D animations (Kahraman \& Demir, 2011) in the instructional process with the advance of computers, tablet or smart phones are also becoming increasingly popular. Since videos and animations have some attributes for facilitating learning, researchers and instructional designers tend to adapt them as instructional technologies to the instructional process. Velázquez-Marcano et al. (2004) argues that using videos may facilitate to construct knowledge about concepts or events and also support to transfer the knowledge. In addition, Yousef, Chatti, and Schroeder (2014) asserted that videos have unique features to enhance or support classroom-based and teacher-led learning approaches. Also animations are considered as a means for supporting to organize the 
knowledge in the memory and facilitate to reorganize the schemas (Liu et al., 2010). Similarly, Xiao (2013) points out that using animations can support learning through the use of new software and hardware techniques. Some positive effects were noticed through 2D animations and the advent of new techniques teachers begun to experience the 3D. Because learning from 3D animations can facilitate learning with 3D objects and allow students to investigate events, objects or concepts more accurately. Researchers concluded that incorporating animations or videos in instruction is useful especially when learning process requires visualization or motion (Seidel, Blomberg, \& Renkl, 2013).

\section{Research Problem}

Since the today's children grow up with computers; they observe, touch, interact, play or solve problems with computers, in other words they live with computers. Thus, they shape some conceptions about computers working principles, capabilities or scopes. The assumption that knowledge of computer concepts contributes to ICT capability (Hammond \& Rogers, 2006) makes computer concepts more important for vocational high school students. Because the students in computer department of the vocational high schools will attend to IT sector. Therefore, if the misconceptions of these students' about IT concepts are not remedied as soon as possible, the lack of their conceptual knowledge may negatively affect to their future professions. In this regard, determining the conceptual understandings and remedying the potential misconceptions may provide valuable insights for students' future work on specific computer processes or larger computer systems.

Considering the potentials of videos and 3D animations, we hypothesized that they can be useful to remedy misconceptions about computer system concepts. In this sense, we implemented the tasks with using videos and 3D animations in and out of the classroom activities. The study attempts to determine vocational high school students' understandings of computer system concepts. In accordance with this aim, the main question was: How do videos and $3 \mathrm{D}$ animations affect remedying misconceptions in the computer system concepts? The following sub-questions were guided to this study:

- What kinds of misconceptions were noticed about computer system concepts among vocational high school students?

- Did using videos and 3D animations in and out of classroom activities differently effect on remedying misconceptions about computer system concepts?

\section{Method}

A quasi-experimental design was employed in the study. Naturally occurring groups of two classes were assigned as two groups. A pretest-posttest nonequivalent control group design was utilized.

\section{Participants}

Students in computer department of the vocational schools attend to these schools for having a profession about IT technologies and have a job as an intermediate member in the IT sector. Since the topics about the basic concepts of computer system are delivered at 10th grade, the 
study is carried out in 10th grade vocational high school classroom. The participants for the study consisted of a total of 34 tenth grade students with an age range of 15-16. One classroom group (CG) with 15 students ( 3 female, 12 male) and one homework group (HG) with 19 students ( 2 female, 17 male). Students in both groups come from similar educational and socio-economic backgrounds.

All of them received one computer literacy course including basic operating system and office software in the previous year. However, none of the participants have sufficient previous conceptual knowledge about the related topics. Therefore, the participants were those who need to improve their conceptual knowledge in order to use for their future jobs.

\section{Data Collection and Analysis}

In the study, a conceptual understanding test, clinical interviews, and observations were used to collect data.

Conceptual Understanding Test (CUT) was a three-phase concept test developed by the researchers according to the most common student alternative conceptions reported in the literature. The concepts were involving the knowledge and understanding of the processes associated with computers basic units. Three-phase concept tests with their potentials in distinguishing correct answers from lack of information, mistakes or incorrect descriptions are preferred in similar studies on conceptual understanding (Choi \& Johnson, 2005). Two experienced IT teachers examined the test for content validity. After a pilot implementation of the test, 25 items was developed for a final form. Cronbach's alpha reliability coefficient of the CUT was found to be 0.73 which can be considered as reliable (DeVellis, 2012). CUT was carried out as pre-test and post-test in order to determine the conceptual change between pre- and post-conceptions.

Observations and Clinical Interviews were used to explain the reasons of the conceptual changes of the students. One of the researchers was also the teacher, so he observed the students' behaviors in the classroom and also he evaluated the students' homework in HG. He used an observation form for addressing participants' use of videos and 3D animations in the classroom. His observations about the behaviors, students' perspectives in the activities and their interactions were noticed after the lessons. Remarkable perspectives are also noted during the course. The observation notes were used to interpret and explain the qualitative data about the conceptual change of the students.

A total of 6 students ( 3 from Classroom Group, 3 from Homework Group) were selected considering their post-test performances (who had better/higher changes in conceptual understandings) for clinical interview. Clinical interview questions were about the reasons of the change in students' answers in pre-tests and post-tests including why they provided the answer. First students' answers were reminded to the students and then their perspectives were gathered about the change. For instance: "Your answer was: Processor is only found in the personal computers, then your answer was changed and you addressed other electronic devices too." 
The instruments used in the study were briefly explained in Figure2.

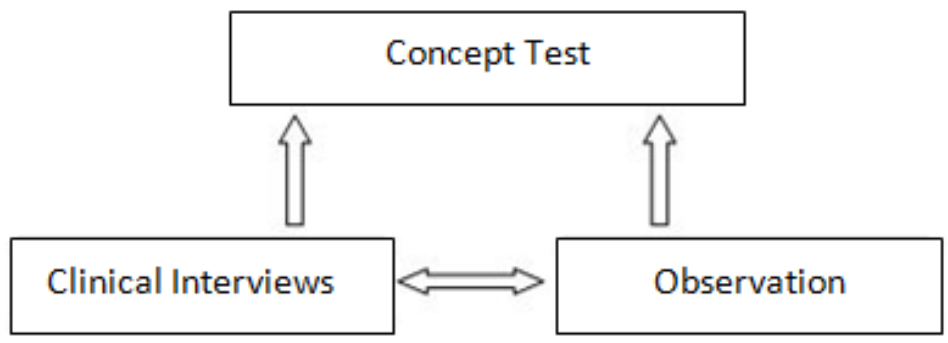

Figure2. Data Collection Tools

\section{Procedures}

The pre-test including the items about the basic concepts of computer system: "memory", "main board", "I/O cards", "disc drives", and "monitors" was administered first. After determining the misconceptions about the basic concepts in the pre-test, videos and 3D animations were developed in accordance with frequently-faced misconceptions. The participants were then directed to use videos and 3D animations for their particular treatment. Videos and 3D animations included the events about the data transmission and processing, working principles in the units, scope of the units. Then videos and 3D animations were covered within a scenario and they were organized on a web site. Screenshots from web interface is shown in Figure1.

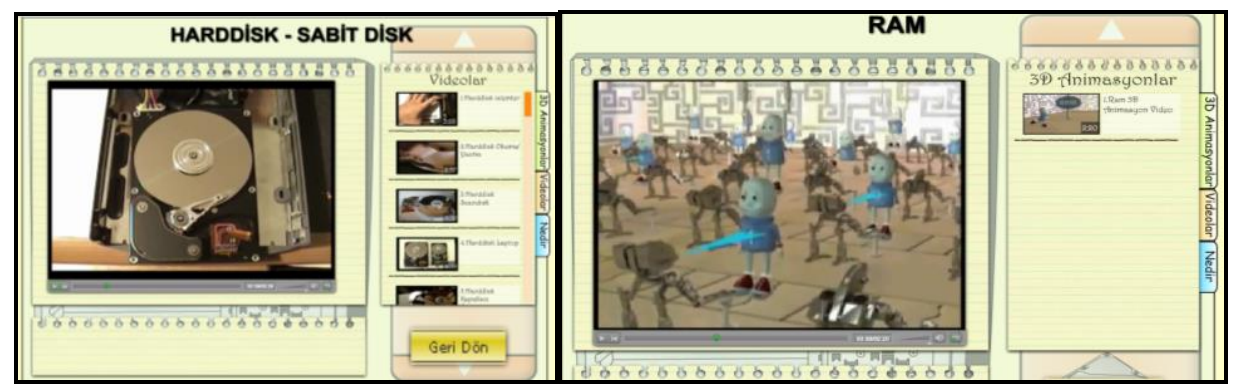

Figure1. View from a Video and a 3D Animation

In the interventions, students in the classroom group received the lessons at PC lab which includes at least one PC per student. They studied with the videos and 3D animations in the classroom. The teacher introduced videos and animations to students with short notices. He provided presentations, questions and answers during sessions in the classroom activities. The teacher sometimes allowed them to work with videos individually or together. He did not spend special effort to support students in order to act in the tasks. He acted as a guide for actions on the videos and 3D animations such suggesting slowing down, replaying, rewind or forwarding.

In the homework group, videos and 3D animations were used in the tasks given as homework. The teacher explained to the students how to use videos and 3D animations in the homework and how to provide details for solutions. The teacher asked students to solve problems about the computer concepts by working with the videos and 3D animations at home. He gave five problems for homework during the treatments and evaluated the homework in the next 
lesson. He asked students to explain how they used videos and animations during the homework period. Then, the post-test was administered to both groups after the intervention.

\section{Analysis}

Students' answers for each item were evaluated by using the grading criteria in Table 1 . This analysis technique was also used in similar studies in order to evaluate the result of threephase tests (Eryilmaz \& Surmeli, 2002). The pre-test scores of CG and HG were compared by using independent t-test over all concepts (memory, main board, graphic card etc.) to determine whether a statistically significant difference between the mean scores of the CG and EG. Since no statistically significant difference between the pre-test results were found, the post-test results were analyzed using the independent t-test to identify the effects of treatment on conceptual changes between two groups. In addition, the change in the pre- and post-test scores within the groups were determined using paired sample t-test.

Table 1. Scoring Criteria for CUT

\begin{tabular}{lllll}
\hline 1.Degree & 2.Degree & 3.Degree & Result & Points \\
\hline True & True & Sure & True & 2 \\
True & True & Neutral & Partially-True & 1 \\
& & Not sure & & \\
True & False & Sure & Partially-True & 1 \\
False & False & Sure & False & 0 \\
& & Neutral & & \\
True & Folsure & Neutral & False & 0 \\
& & Not sure & & \\
\hline
\end{tabular}

Clinical interviews were analyzed via content analysis and coded thematically by associating students' perspectives with the features of videos and 3D animations. First, the two researchers coded the statements individually/independently and then they discussed these together until they come to an exact agreement about the codes. The observation notes were taken in the classroom by one of the researchers and they were used as supporting evidences in interpreting the clinical interview data.

\section{Results}

CUT was administered to both groups as a pre-test and post-test. The mean scores of the pretest were almost similar between the two groups: (CG: $M=8.23$; $S D=4.94$ ) and (HG: $M=8.18$; $\mathrm{SD}=4.79)$ and no statistically significant difference between the mean scores of the groups $(t(32)=1.12, p=0.14)$ were found. Pre-test results indicated that majority of students had misconceptions about the basic concepts of computer systems. Because similar backgrounds about the conceptual knowledge was occurred before the treatments, independent t-test was used to reveal the conceptual change after the intervention.

The mean scores for the groups were (CG: $M=13.66, S D=6.27)$ and (HG:M $=10.78, S D=$ 3.72) which were almost similar. Also, independent t-test results indicated that there was no 
statistically significant difference between the mean post-test scores of the groups $(t(32)$ $=1.66, p=0.10$ ).

\section{Changes in Conceptual Understandings}

Figure3 outlines the results from pre-test and post-tests results of the students who used videos and 3D animations in the classroom (CG).

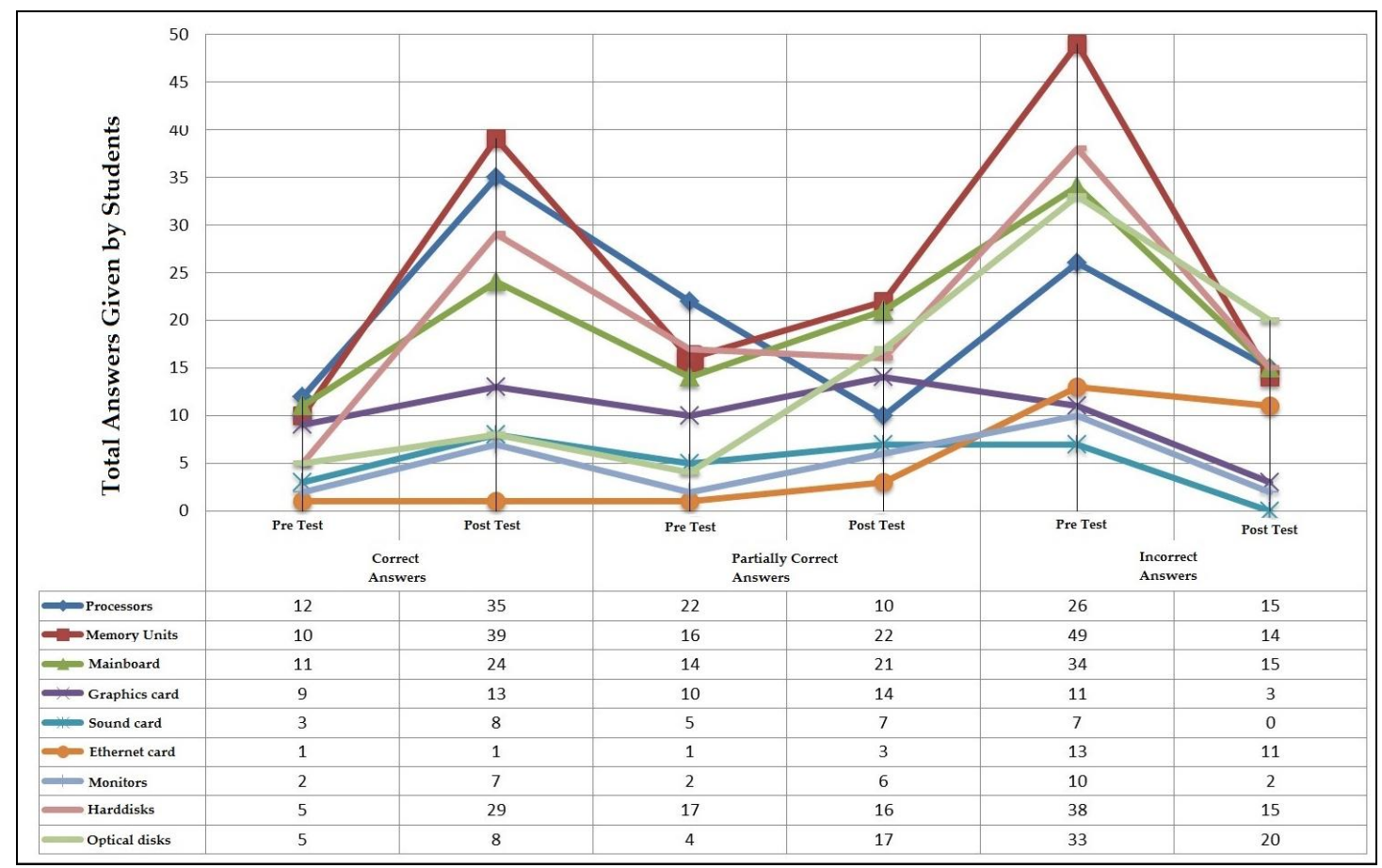

Figure3. Pre-test and Post-test Results (CG)

It is seen that the number of correct answers of CG group students' increased in the post-test. Some of the incorrect answers in pre-test were changed to correct or partially correct in the post-test. The correct answers about processors and memory units were considerably increased. The highest change in incorrect answers was in the memory concept which was decreased from 49 to 14 . Also a distinct increase in correct answers was observed in harddisk unit which was 5 at the beginning and grow to 29 correct answers after the intervention. In addition, the total incorrect answers were decreased nearly a half of the initial incorrect answers. Surprisingly none of the students' answers were incorrect about sound card in the post-test. While partially correct answers were increased in some units, some are also decreased. For instance, in mainboard unit the partially correct answers were increased from 14 to 21; however, at this time the incorrect answers were decreased and correct answers were increased. Similarly in post-test, with the intervention students partially correct answers were to increased from 4 to 17 . In almost all units, the incorrect answers are more than partially correct and incorrect answers. In the post-test, except optical disk and ethernet card units, the correct answers were more than partially correct and incorrect answers. Thus, it is seen that when the incorrect answers have a prominent decrease, it has a positive influence on the correct answers or partially correct answers of the unit. 
The results of pre-test and post-tests of HG students were shown in Figure 4.

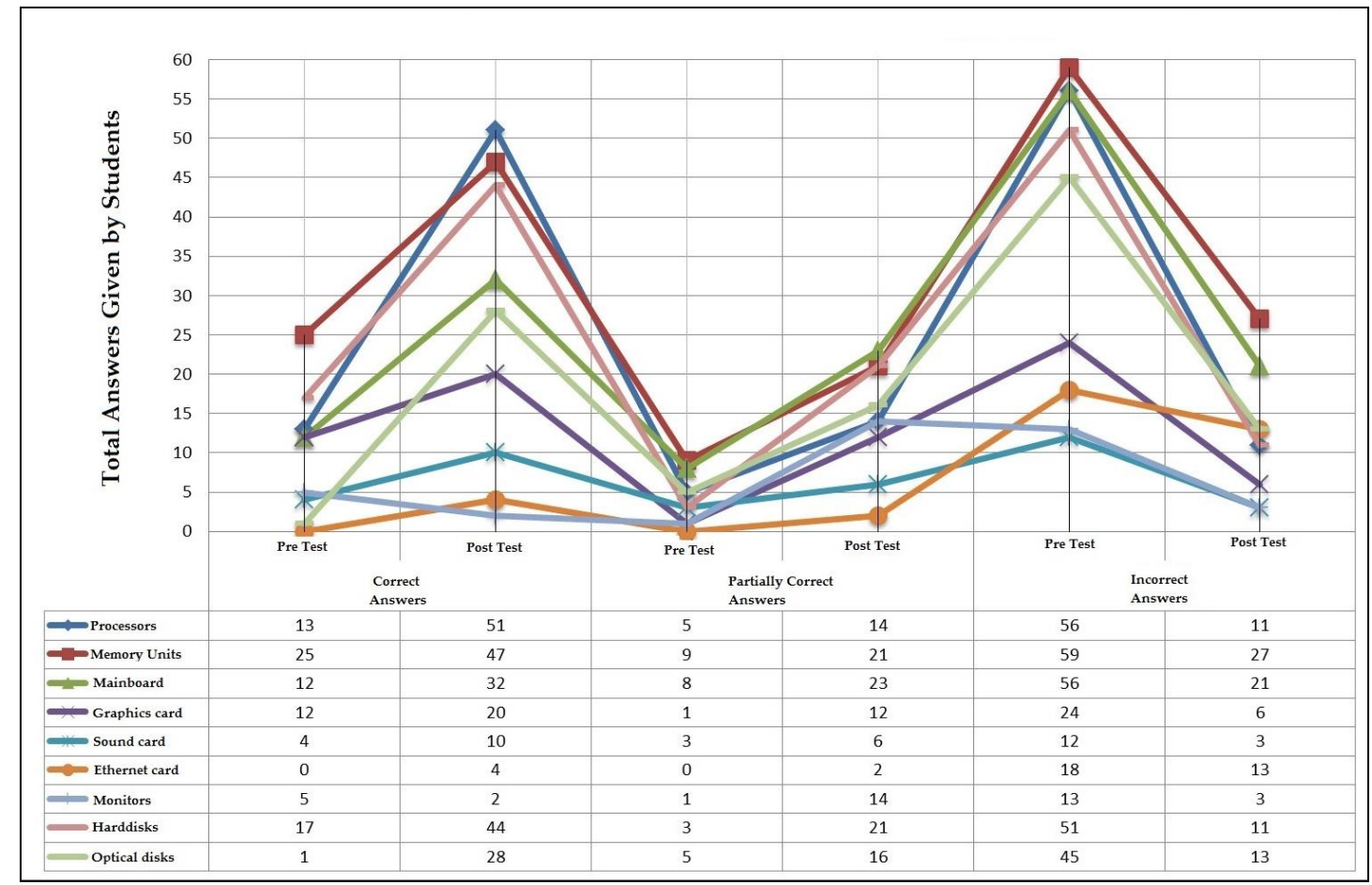

Figure 4. Pre-test and Post-test Data for Homework Group

The results show that HG group students' correct answers were explicitly increased in all units in the post-test. Numerous incorrect answers in pre-test were changed to correct or partially correct. For instance, while the number of correct answers were 13 about the processors concepts in pre-test, 51 correct answers were found after the treatment in HG. In a similar vein, while the correct answers in memory mainboard and harddisk units had a distinct increase (respectively 25 to $47 ; 12$ to $32 ; 12$ to 20 ) and the incorrect answers were decreased in a proportional manner. As observed in $\mathrm{CG}$, correct answers in harddisk are increased with the intervention (17 to 44). In all units, the partial correct answers are increased and incorrect answers are decreased in all units. The correctness in processor, memory, mainboard, harddisk and optical disk units were considerable that more than the half of the incorrect answers were corrected. That is 56 to 11 in processors, 59 to 27 in memory units, 56 to 21 in mainboard, 51 to 11 in harddisk and 45 to 13 in optical disks. Overall, when the pre-test and post-test scores of two group students were examined, it was seen that the performance of students in both groups increased from pre-test to post-test.

Independent sample t-test was carried out to define whether there is a significant difference between the post-test scores of the group, and the result of the test was shown in Table 2 . The mean scores for the groups were (CG: $M=13.66, S D=6.27$ ) and ( $H G: M=10.78, S D=3.72$ ) which were almost similar. Also, independent t-test results indicated that there was no statistically significant difference between the mean post-test scores of the groups $(t(32)$ $=1.66, p=0.10$ ) (See Table 2). 
Table 2. t-test Results of Posttests between CG and HG

\begin{tabular}{lllllll}
\hline Pre-test & $\mathrm{N}$ & $\mathrm{M}$ & $\mathrm{SD}$ & $\mathrm{df}$ & $\mathrm{t}$ & $\mathrm{p}$ \\
\hline CG (Classroom Group) & 15 & 13.66 & 6.27 & 32 & \multirow{2}{*}{1.66} & .10 \\
HG (Homework Group) & 19 & 10.78 & 3.72 & & & \\
\hline$(\mathrm{p}>0.05)$ & & & & & &
\end{tabular}

The results reflected that while the mean values of CG post-test scores in all topics were higher than HG, the instructional process in both groups provided similar effects in both groups. The change in pre-test and post-test results of the CG and HG students showed that using videos and $3 \mathrm{D}$ animations both in the classroom and in the homework activities provided significant impact in remedying misconceptions.

\section{Misconceptions in Basic Computer Units}

The participants' responses indicated that students had various kinds of misconceptions about computer units at the beginning of the study. Some of the misconceptions were depending on the terminology and some others were related to the working principles of the hardware unit and its relations with the operating system. Frequently-faced misconceptions about the basic computer system units were determined as follows:

Processor: It is only found in the computers. The power of computers depends on the speed of the processors.

Main board: It is only responsible to transmit data. It is not responsible to control the data traffic, the transmission is provided by the software.

Ethernet card: The form of the data does not change when data goes from one to another computer.

Video card: The quality of the image depends on the quality of the monitor; the display card does not play any role.

Sound card: You do not need an extra card to provide a sound from the computer.

Memory: The terms ram and memory reflect different things. There is no need for electrical energy to store data.

Hard disk: CPU search for data in the hard disk first. The data is temporarily stored in the hard disk.

Optical disks: Videos and music are stored in different locations in DVDs.

Monitor: Do not require extra tool to display the texts.

\section{Students' Perspectives about the Changes in Conceptual Understandings}

Students' perspectives were gathered from the interviewees who were chosen from CG and HG among the students having a prominent change in the conceptual understandings after the intervention. Students were asked about how they corrected their previous misconceptions. The questions were asked to the students in terms of "whys", rather than "whats" concerning 
the relationships between their conceptual understandings and the features of the videos and 3D animations. For instance, about the sound card, the researcher asked questions such as: "In the pre-test you answered that computers do not need extra hardware for sound; but in posttest you changed your answer, why did you think so...?". In addition, some questions were directed to the both of the interviewees in order to reveal general perspectives through the videos and 3D animations. For instance, CG group students were asked "What are the differences between lessons with the video and 3D animations and your previous lessons?", "Which way do you think the new materials impact your knowledge?" Also, HG group students answered the questions "What do you think about the process of homework with video and 3D animations?" The results of thematic analysis were shown in Figure 5.

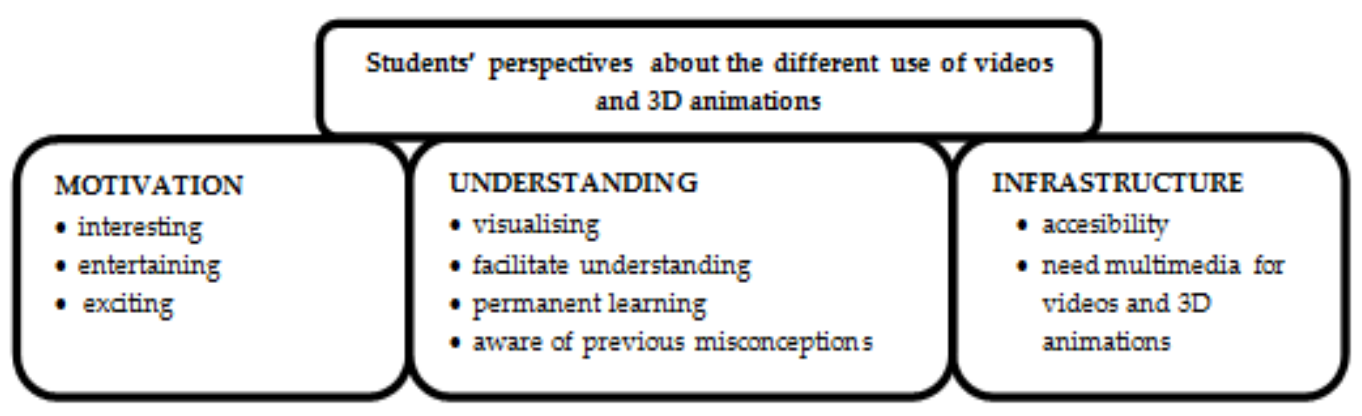

Figure 5. Main Themes from Clinical Interviews

In the clinical interviews, students were provided various data about the relationship between the characteristics of videos and 3D animations and their conceptual changes. For instance; S1 from CG indicated that using materials in the classroom activities was facilitated to understand the concepts clearly. He expressed that videos and 3D animations provided visualization and improved motivation. Besides he expressed that students may reuse the materials by using the stop and replay features whenever they want. S2 also focused on visualization, motivation and permanent learning. One of his expressions was: "I understood deeply with videos. Thanks to the visuals, they helped me correct something wrong in my mind by concretizing the abstract concepts." S3 specified that, studying on the activities by herself facilitated her to understand the concepts in higher level. He stated that; "The videos and animations were more helpful on understanding without memorizing. It was more permanent because of visualization. It was not boring. When I located the components on the mainboard, I understood better where the location of the units was." Also S2 expressed that learning with videos and 3D animations was easy and more enjoyable.

Overall, the interviewees in CG commonly stated that instructional process with videos and 3D animations facilitated understanding and remedied some of the misconceptions, and also increased the motivation. For instance, S6 from the HG specified: "I get rid to access to the videos from where I want. I did not feel boring. I completed the homework and I could solve the problems in the homework." In addition, S4 from the HG expressed that he could remedy some of the misconceptions. In the following statement: "Doing homework with using videos was more supportive. I think the computer units are more visible in my mind now. The teacher provided us somewhat difficult problems but I could find the answers by following the videos." Similarly, S5 from HG pointed out that internet connection problems sometimes negatively affected to his motivation. Overall; similar to the CG students, the interviewees in the HG group perceieved that using videos and 3D animations in homework activities facilitated their comprehension, increased the motivation and supported the permanent learning. 
In addition, the observations indicated that, the CG students could use the videos and 3D animations in a proper and sufficient way. Only a few technical problems were faced in the classroom. It was often observed that students felt very exciting and comfortable during the practice. Also, the guidance of the teacher was sometimes important for CG group students to construct conceptual knowledge by using videos and 3D animations.

\section{Discussion}

Vocational high school students in the computer department should learn the concepts about their future professions. In this sense various multimedia are tended to be used in remedying the obstacles in teaching abstract concepts of IT courses. This study explores the effect of the videos and 3D animations on conceptual understandings about computer concepts.

It was observed that various kinds of misconceptions existed in the computer system units such as ethernet card, ram, hard disk, optic disk, processor or graphic card. Some of the students considered that processors only exist in the personal computers, and the power of the computer system depends on the speed of the processor. The storage devices such as ram memory and hard disks were often confused. Also a number of students ignored the graphic cards and they considered that quality of the images only depends on the quality of the monitor. Similar misconceptions were also noticed in the previous studies (Cakiroglu et al., 2007). A number of students also imagined that data is transmitted on the mainboard but data traffic is related to the mainboard. Only a few students had misunderstandings about the principles of ethernet card that it sends data from one computer to another without any change in the journey. Hammond and Rogers (2006) argue that one of the factors of this kind of difference is students' home experiences. However, in this study little differences occur among students' home experiences, students' computer use in the schools covers a long period of their daily life so the differences do not completely confirm their idea.

Videos and 3D animations substantially affected various senses (Choi \&Yang, 2011; Huk et al., 2003; Kahraman \& Demir, 2011; Wu \& Chiang, 2012). The videos and 3D animations with their authentic features facilitated understanding and transferring the knowledge about principles of the computer system (Ates \& Polat, 2005; Bulbul, 2009; Choi \&Yang, 2011). For instance, the read and write operations on the hard disk and the movements of the read-write head was followed by the students by using stop-start or slow down, replay features in the videos and also the enlarging feature in the 3D animations. Thanks to video's replay features that students could follow the videos whenever they want and they could interpret the related concepts. To that end, they benefited from videos easily within their own speed. One of the main impacts of the videos was to enhance retention and motivation. Some studies in other courses also addressed similar results about retention and motivation effect of the videos (Choi \& Johnson, 2005; Choi \&Yang, 2011; Dongsong et al., 2005; Sykes, 2012; Yolcu, 2009). Learning with 3D animations also contributed to enhance students' motivation by drawing their attention to the concepts (Kahraman \& Demir, 2011; Liu et al., 2010). In this circumstance, students generally pay low attention to some abstract and difficult topics in traditional teaching methods; they could imagine the working principles of the computer system by the videos and 3D animations. Similarly, Arici and Dalkilic (2006) reported that 3D animations may facilitate concretizing abstract concepts in mind. In addition, some studies also confirmed that misconceptions in IT courses may be remedied via animations (Cakiroglu et al, 2007; Dalton, 2003; Kayali \& Tarhan, 2004; Liu et al., 2010). Some other studies also pointed out those using animations may 
enhance meaningful understanding with the visualization feature (Akilli \& Seven, 2014; Huk et al., 2003; Kahraman \& Demir, 2011; Korakakis, et al., 2009; Robertson, Card, \& Mackinlay, 1993; Wu \& Chiang, 2012).

On the other hand, quantitative results indicated that misconceptions about the concepts existed in all concepts of the computer system. The videos and 3D animations used in the classroom and in the homework activities both contributed positively to remedying misconceptions. Students especially enhanced their knowledge about the scopes and working principles of the computer system units. In this sense, the videos and 3D animations were supported to associate the previous knowledge with the new knowledge. While students in the classroom activities could ask questions about the concepts, in the homework activities they did not have this opportunity but this situation did not affect the difference of conceptual change in two groups. This is may be due to the various advantages of videos and 3D animations in different activities. Thus, to be allowed to ask questions to the teacher is an advantage for the classroom group, accessing the videos animation 3D animations anywhere was an advantage for the homework group. In addition, the problems given in the homework were useful for the students. One reason may be for this situation is that the homework for the HG included the concepts in which the students faced misconceptions intensively. Also, the videos and 3D animations allowed students to study within their individual preferences. Although the number of videos and 3D animations were somewhat limited in some concepts, the teacher used them in a balanced way in the classroom activities and also in the tasks of the homework group. In terms of the number of the videos and 3D animations, an inverse relationship may be drawn between the quantity of the materials and their effects on conceptual understanding. Hence, when the number of videos of 3D animations was quite limited, the number of incorrect or partly true answers was high. When the number of 3D animations was less than the number of videos, the conceptual changes were not realized as expected level. This was observed especially in the ethernet card and sound card units.

In order to analyze the data about misconceptions, a three-phase concept test was used in the present study. The results also confirmed that the test was useful to determine the change in the misconceptions. Of course, this study has some limitations in certain respects. The low internet connection sometimes negatively affected the performance of a few students. In this case, the students somehow felt bored during completion of their homework. In addition, although students' homework were evaluated in the classroom, it was difficult to follow how students achieved the tasks at home. Likewise, the CG students in classroom somewhat interacted with each other which could not be under controlled.

\section{Conclusion and Recommendations}

Based on the post-test results no significant difference was found between using videos and $3 \mathrm{D}$ animations in the classroom and in the homework activities. The different use of video and 3D animations may positively affect remedying misconceptions about basic computer units. This may be due to the well-designed videos and 3D materials and the teacher's effective use of them. Following the pieces of the units, listening to the narrations about the units, investigating the motions of the small pieces and having opportunities to interact with the units were the prominent features of videos and 3D animations. Videos and 3D animations supported concretization of abstract concepts, increased student engagement in the tasks, enhanced motivation, and improved spatial visualization ability. These contributions somehow directly or indirectly affected remedying the misconceptions. In this way, the visual and audial 
effects of video and 3D animations facilitate conceptual learning. Moreover, while the quality of videos and 3D animations are important for the success of the implementation, the quantity were also related to the success of remedying misconceptions.

Moreover, teachers' role in the use of videos and 3D animations had a positive contribution in the success of remedying misconceptions in the classroom. The prominent roles were acting as guidance to the students, monitoring students, and focusing on the frequently observed misconceptions. The teachers' role outside the classroom was administering the projects, following the activities, and evaluating the homework step by step in the classroom. Thus, teachers' active role in and out the class activities affected to the conceptual understandings. Besides, the results indicated that the three-phase concept test was a useful way to determine the misconceptions. In future studies, the use of video and 3D animations integrated with other instructional techniques may be investigated. Finally, this study is hoped to provide a useful insight for operationalizing the potentials of videos and 3D animations in remedying various misconceptions in some other abstract topics.

\section{References}

Akilli, M., \& Seven, S. (2014). The effects of 3d computer models to academic achievement and spatial ability: Atomic models. Turkish Journal of Education, 3(1), 11-23.

Arici, N. \& Dalkilic, E. (2006). The contribution of animations to computer assisted education: an application sample. Kastamonu Education Journal, 14(2), 421-430.

Arslan, H. O., Cigdemoglu, C., \& Moseley, C. (2012). A three-tier diagnostic test to assess preservice teachers' misconceptions about global warming, greenhouse effect, ozone layer depletion, and acid rain. International Journal of Science Education, 34(11), 1667-1686.

Ates, S., \& Polat, M. (2005). The effects of learning cycle method on removing misconceptions related to electric circuits. Hacettepe University Journal of Education, 28, 39-47.

Bernhard, J. (2000). Do active engagement curricula give long-lived conceptual understanding? Physics Teacher Education Beyond, 749-752.

Baki, A., Kosa, T., \& Guven, B. (2011). A comparative study of the effects of dynamic geometry software and physical manipulatives on pre-service mathematics teachers' spatial visualization skills. British Journal of Educational Technology, 42(2), 291-310.

Bulbul, O. (2009). Simulations and animations effects in computer assisted instruction on academic success and retention when teaching of optic unit in physics (Unpublished master's thesis). Cukurova University, Adana, Turkey.

Cakiroglu, U., Cebi, A., \& Bezir, Ç. (2007). Design and implementation of an instructional software for teaching information technologies. Gaziosmanpasa University Journal of Social Sciences Research, 2, 86-97.

Caleon, I. \& Subramaniam, R. (2010). Development and application of a three-tier diagnostic test to assess secondary students' understanding of waves. International Journal of Science Education, 32(7), 939-961.

Chandrasegaran, A. L., Treagust, D. F., \& Mocerino, M. (2007). The development of a two-tier multiple-choice diagnostic instrument for evaluating secondary school students' ability to describe and explain chemical reactions using multiple levels of representation. Chemistry Education Research and Practice, 8(3), 293-307. 
Choi, H. \& Johnson, S. D. (2005). The effect of context-based video instruction on learning and motivation in online courses. American Journal of Distance Education, 19(4), 215-227.

Choi, H. \& Yang, M. (2011). The effect of problem-based video instruction on student satisfaction, empathy, and learning achievement in the Korean teacher education context. Higher Education, 5, 551-555.

Clark, R. E., \& Choi, S. (2005). Five design principles for experiments on the effects of animated pedagogical agents. Journal of Educational Computing Research, 32(3), 209-225.

Crawford, K., Neve, L., Pearson, M., and Bridget, S. (1999, September) Creative tensions and disrupted routines: The impact of the Internet on primary children's understanding of the world. Paper presented at the British Educational Research Association Annual Conference. University of Sussex, England.

Dalton, R. M. (2003). The development of students' mental models of chemical substances and processes at the molecular level. (Unpublished doctoral dissertation). Western Sydney University, Australia.

DeVellis, R.F. (2012). Scale development: Theory and applications. Los Angeles: Sage.

Dongsong, Z., Lina, Z., \& Robert, O. B., Jay, F. Nunamaker, J. R. (2005). Instructional video in elearning: Assessing the impact of interactive video on learning effectiveness. Information \& Management, $43,15-27$.

Driver, R., Asoko, H., Leach, J., Mortimer, E., and Scott, P. (1994). Constructing scientific knowledge in the classroom. Educational Researcher, 23, 5-12.

Driver, R., Leach, J., Miller, R., and Scott, P. (1996). Young people's images of science. Buckingham, England: Open University Press.

Eryilmaz, A. \& Surmeli, E. (2002). Identifying students' misconception on heat and temperature through three-tier questions. Proceedings of the 5 th National Conference on Science and Mathematics Education. Retrieved on 15 April 2017 from http://www.fedu.metu.edu.tr /ufbmek-5/b_kitabi/PDF/Fizik/Bildiri/t110d.pdf

Feiereisen, S., Wong, V., \& Broderick, A. J. (2008). Analogies and mental simulations in learning for really new products: The role of visual attention. Journal of Product Innovation Management, 25(6), 593-607.

Gal-Ezer, J., \& Zur, E. (2004). The efficiency of algorithms-misconceptions. Computers \& Education, 42, 215-226.

Galloway, J. P. (1990). Misconceptions of computing concepts among preservice teachers. Journal of Research on Computing in Education, 22(4), 413-430.

Gurbuz, R. \& Birgin, O. (2012). The effect of computer-assisted teaching on remedying misconceptions: The case of the subject "probability". Computers \& Education, 58(3), 931-941.

Hammond, M. \& Rogers, P. (2007). An investigation of children's conceptualisation of computers and how they work. Education and Information Technologies, 12(1), 3-15.

Hay, D. B. (2007). Using concept maps to measure deep, surface and non-learning outcomes. Studies in Higher Education, 32(1), 39-57. 
Huang, T. H., Liu, Y. C., \& Shiu, C. Y. (2008). Construction of an online learning system for decimal numbers through the use of cognitive conflict strategy. Computers \& Education, 50, 61-76.

Huk, T. Steinke, M., \& Floto, C. (2003). Computer animations as learning objects: what is an efficient instructional design, and for whom? Proceedings of the IADIS International Conference www/Internet (pp. 1187-1190). Algarve, Portugal.

Kahraman, S. \& Demir, Y. (2011). The effects of computer-based 3d instruction materials on misconceptions: Atomic structure and orbitals. Journal of Education Faculty, 13(1), 173188.

Kayali, H. A., \& Tarhan, I. (2004). Application of a guide material based on constructivism-active learning to remedy misconceptions on "Ionic bonding". Hacettepe University Journal of Education, 27, 145-154.

Kizilcik, H. S. \& Gunes, B. (2011). Developing three-tire misconception test about regular circular motion. Hacettepe University Journal of Education, 41, 278-292.

Korakakis, G., Pavlatou, E. A., Palyvos, J. A., \& Spyrellis, N. (2009). 3D visualization types in multimedia applications for science learning: A case study for 8 th grade students in Greece. Computers \& Education, 52(2), 390-401.

Kuru, I. \& Gunes, B. (2005). Misconceptions of grade-10 students about force. Journal of Gazi Educational Faculty, 25(2), 1-17.

Lanie, A. D., Jayaratne, T. E., Sheldon, J. P., Kardia, S. L., Anderson, E. S., Feldbaum, M., \& Petty, E. M. (2004). Exploring the public understanding of basic genetic concepts. Journal of Genetic Counseling, 13(4), 305-320.

Liu, T.C., Lin, Y.C., \& Kinshuk (2010). The application of Simulation-Assisted Learning Statistics (SALS) for correcting misconception sand improving understanding of correlation. Journal of Computer Assisted Learning, 26, 143-158.

Mumtaz, S. (2002). Children's conception of information communications technology. Education and Information Technologies, 7(2), 155-168.

Oliver, R. (1994). Information Technology Courses in Teacher Education: The Need for Integration. Journal of Information Technology for Teacher Education, 3(2), 135-146.

Papastergiou, M. (2005). Students' mental models of the Internet and their didactical exploitation in informatics education. Education and Information Technologies, 10(4), 341-360.

Read, J., MacFarlane, S., \& Casey, C. (2002). Requirements for the design of a handwriting recognition based writing environment for children. In S. Fincher, P. Markopoulos, D. Moore, \& R. Ruddle (Eds.), Proceedings of the 8th international EARLI SIG Handwriting Conference (pp.81-87). London: Springer-Verlag.

Rittle-Johnson, B., Siegler, R. S., \& Alibali, M. W. (2001). Developing conceptual understanding and procedural skill in mathematics: An iterative process. Journal of Educational Psychology, 93(2), 346.

Robertson, G. G., Card, S. K., \& Mackinlay, J. D. (1993). Information visualization using 3D interactive animation. Communications of the ACM, 36(4), 57-71. 
Roussou, M. (2004). Learning by doing and learning through play: an exploration of interactivity in virtual environments for children. Computers in Entertainment (CIE), 2(1), 10-10.

Rucker, M. T. \& Pinkwart, N. (2016). Review and discussion of children's conceptions of computers. Journal of Science Education and Technology, 25(2), 274-283.

Sanger, M. J. \& Greenbowe, T. J. (2000). Addressing student misconceptions concerning electron flow in aqueous solutions with instruction including computer animations and conceptual change strategies. International Journal of Science Education, 22(5), 521-537.

Seidel, T., Blomberg, G., \& Renkl, A. (2013). Instructional strategies for using video in teacher education. Teaching and Teacher Education, 34, 56-65.

Sykes, R. (2012). The impact on student learning outcomes of video when used as a primary teaching tool in the internet hybrid classroom (Unpublished doctoral dissertation). East Tennessee State University, Johnson City, TN, USA.

Treagust, D. F. (1988). Development and use of diagnostic tests to evaluate students' misconceptions in science. International Journal of Science Education, 10(2), 159-169.

Van Boxtel, C., Van der Linden, J., \& Kanselaar, G. (2000). Collaborative learning tasks and the elaboration of conceptual knowledge. Learning and Instruction, 10(4), 311-330.

Velázquez-Marcano, A., Williamson, V. M., Ashkenazi, G., Tasker, R., \& Williamson, K. C. (2004). The use of video demonstrations and particulate animation in general chemistry. Journal of Science Education and Technology, 13(3), 315-323.

Vural, O. \& Zellner, R. (2010). Using concept mapping in video-based learning. University of Gaziantep Journal of Social Sciences, 9(3), 747-757.

Wu, C. F. \& Chiang, M. C. (2012). Effectiveness of applying 2d static depictions and 3D Animations to orthographic views learning in graphical course. Computers \& Education, 63, 28-42.

Xiao, L. (2013) Animation Trends in Education, International Journal of Information and Education Technology, 3(3), 286-289.

Yolcu, M. (2009). Comparison of computer adaptive individual video tutoring with whole class video lessons (Unpublished master's thesis). Gazi University, Ankara, Turkey.

Yousef, A. M. F., Chatti, M. A., \& Schroeder, U. (2014). Video-based learning: A critical analysis of the research published in 2003-2013 and future visions. In eLmL 2014, The Sixth International Conference on Mobile, Hybrid, and On-line Learning (pp. 112-119). Retrieved on 15 April 2017 from http://www.thinkmind.org/download.php?articleid= elml_2014_5_30_50050

Correspondence: Unal Cakiroglu, Associate Professor, Department of Computer Education and Instructional Technologies, Fatih Faculty of Education, Karadeniz Technical University, Trabzon, Turkey. 